\title{
Psychological Wellbeing and Communication Styles among Medical-Surgical Nursing Students
}

\author{
Fatma Hussein Ramadan and Rasha Aly Yakout \\ Assistant Prof. of Psychiatric Nursing and Mental Health Department, Lecturer of Medical-Surgical Nursing \\ Department, Faculty of Nursing, Alexandria University, Alexandria, Egypt.
}

\begin{abstract}
The more psychologically healthy the nursing students are, the more likely they will be productive and successful in their academic and clinical training. Communication skills used in nursing to provide emotional support, information and feedback, giving hope to patients, and help them to cope with anxiety. This study aimed to investigate the relationship between psychological wellbeing and communication styles among Medical-surgical university student. A descriptive -correlation study was conducted on 174 nursing students who were enrolled in Medical- Surgical Nursing III at Medical- Surgical department, Faculty of Nursing, Alexandria University. Three tools were used for collecting the data: Tool I: Socio-demographic characteristics structured questionnaire sheet, Tool II: Ryff's Psychological Wellbeing (RPWB) scale and Tool III: Communication style questionnaire. Results of the present study revealed that combiner style of communication was significantly and positively correlated to positive relation dimension of psychological wellbeing. Accordingly, a training program to equip nursing students with communication skills is of paramount importance in helping students to promote their psychological wellbeing. Student nurses should be connected to an interactive web wellness portal with tools and resources for optimal psychological wellbeing.

Keywords: Psychological wellbeing, Communication styles.
\end{abstract}

\section{Introduction}

The concept of wellbeing, is expressed as "subjective wellbeing, "psychological wellbeing", "happiness" "health and happiness", or "quality of life". In psychological studies it is generally labeled as "mental health" or "psychological health" (Galinha\& Pais-Ribeiro 2011). Considering with the psychological functioning approach, wellbeing focuses on living life fully and deeply to retrieve satisfaction and conceptually it refers to the "psychological well-being" (Deci\& Ryan; 2008). Psychological wellbeing or mental health can be characterized by its components that determine an individual's positive state. These components include: personal growth, self-acceptance, purpose in life, autonomy, positive relation with others, and environmental mastery (Shojaee\& French2014).The psychological wellbeing of nursing students is a very important component in the training and development of future nurses(Ratanasiripong and Wang 2011). During clinical training, as well as after graduation, nursing students and nurses work in a wide variety of settings that present them with various levels of challenges to provide good patient care. Some of the current challenges that nursing students face include changes in the healthcare delivery system, nursing shortages, emotional exhaustion, and stress and fatigue from nursing school (Andrews and Wan 2009; Nayeri et al., 2009; Rella et al., 2009). Moreover, the evolution of health care and the presence of more acutely ill patients require changes to be made to nursing curricula to accommodate for the advancements. Curriculum enhancements result in information overload, additional emphasis on critical thinking and problem solving, and more rigorous competency assessments that are based on performance examinations and demonstration of clinical skills (Shultz 2011). Medical-Surgical nursing students are required to possess more theoretical knowledge and more refined clinical judgment skills than ever. Changes to the nursing curriculum lead to a more rigorous course load and a more competitive and stressful learning environment for Medical -Surgical nursing students. Increased levels of stress may lead to poor academic performance, burn-out, and the development of inadequate coping mechanisms. Gibbons (2010) and Jimenez et al. (2010) investigated the impact of stress on nursing students enrolled in a three-year nursing program. They found that second year students reported poorer health and more psychic anxiety than first year and third year students. The more psychologically healthy the nursing students are, the more likely they will be productive and successful in their academic and clinical training. Ultimately, healthy and productive nurses will be able to communicate well with patients, families, physicians, and other healthcare teams, handle the challenges of the nursing profession and provide good patient care (Andrews and Wan 2009). On the other hand, psychological distress among nursing students can result in the possession of many negative personal thoughts and emotions that may affect their communication abilities. Hishinuma et al (2012) indicated that poor psychological wellbeing was related inversely to ineffective communication among nursing students. 
Communication is a vital element in all nursing activities, including prevention, treatment, rehabilitation, education, and health promotion (Kourkouta\& Papathanasiou, 2014). Despite the effect of communication skills on the quality of nursing care and patient improvement and participation in care, the results of different researches showed that nurses were not successful in communicating with patients and families (Chant et al. 2002; McCabe, 2004; Zamani et al. 2004). Sarvestaniet al. (2013) found that the majority of nurses communicated with patients for a very short period of time, they did not show empathy to the patients, and their communication was always about physical needs and little attention was paid to psychological needs. Moreover, Xie et al. (2013) showed that the majority of nursing students had poor skills in clinical, treatment, and interpersonal communication .Utilizing effective communication by nurses could increase patient satisfaction and trust among nurses, patients, and family members and also decrease the patients' physical problems such as increasing blood pressure, pain, and anxiety during hospitalization (Reader, et al. 2007).On the other hand, failure in communication could lead to stress, errors in diagnosis, decrease of patient participation in care plans and information exchange, and poor outcomes (Leonard, et al 2005; Meyer \&Arnheim, 2002). A study showed that most medical errors were not really due to defect in medical technologies or negligence of healthcare providers; rather, they were absolutely related to ineffective communication between patients and physicians (Xie et al., 2013).f nurses want to provide a qualified professional care, they have to be able to communicate well with patients, families, physicians, and other healthcare teams. Communication with patients is the most important aspect of professional nursing whose failure can lead to ineffectiveness of nurses' and other healthcare teams' potentials (J. E. Liu, Wong, Xue, \&Xu, 2007). Clinical communication skill is defined as communicating with patients, their family members, and other healthcare teams (J. F. Xie, Ding, Wang, \& Liu, 2013).Literature showed that good communication could increase patient satisfaction and trust among nurses, patients, and family members and also decrease the patients' Communication is a vital element in nursing in all areas of activity, including prevention, treatment, rehabilitation, education, and health promotion (Kourkouta\& Papathanasiou, 2014 ). If nurses want to provide a qualified professional care, they have to be able to communicate well with patients, families, physicians, and other healthcare teams. Communication with patients is the most important aspect of professional nursing whose failure can lead to ineffectiveness of nurses' and other healthcare teams' potentials Literature showed that good communication could increase patient satisfaction and trust among nurses, patients, and family members and also decrease the patients 'If nurses want to provide a qualified professional care, they have to be able to communicate well with patients, families, physicians, and other healthcare teams. Communication with patients is the most important aspect of professional nursing whose failure can lead to ineffectiveness of nurses' and other healthcare teams' potentials (J. E. Liu, Wong, Xue, \&Xu, 2007). Clinical communication skill is defined as communicating with patients, their family members, and other healthcare teams (J. F. Xie, Ding, Wang, \& Liu, 2013).Literature showed that good communication could increase patient satisfaction and trust among nurses, patients, and family members and also decrease the patients' On the other hand, failure in communication could lead to stress, errors in diagnosis, decrease of patient participation in care plans and information exchange, poor outcomes, Communication style refers to the manner in which an individual gives and receives information. There are four communication styles namely; active, connector, theorist and purposeful communication styles. Each style has its own advantages and challenges. Communication style can change over time due to what type of communication is being rewarded in current situation and personal relationships. It is driven by personal needs for control, safety, order, recognition, achievement, or affiliation (Ferguson2006, Jones 2015). People with active style of communication are direct and straightforward; they get to the point quickly and keep things moving. They tend to make quick decisions and sum things up swiftly. In spite of that, they may need to improve their listening skills and ability to empathize. Whereas, People with connector style like to take time to relate to and connect with others. They show empathy and appreciation. They tend to listen more than talk . They are usually optimistic and positive and find conversations that help others feel positive and confident particularly rewarding. Nevertheless, connectors are sensitive and greatly influenced by their feelings and emotions. Thus may lead them to be subjective and intuitive in many encountered situations. Also they less assertive and dislike conversations that lead to conflict (Bernstein 2016). On the other hand, theorists tend to talk about ideas and information. Their aim is to get information that will help them solve or discover something or provide new knowledge rather than feelings and relationships. Although they might not say a lot, inside their head is an active world of ideas and possibilities. They would rather say nothing than say something wrong. Theorist's body language is usually quite controlled and so may be hard for others to read. They could benefit from empathizing and expressing and responding to feelings (Hasson 2015).Purposeful communicators like to be clear about the aim of a conversation, to stay on track and for everyone to remain respectful, with no interrupting. They prefer others to complete their thoughts and finish what they are talking about before moving on to a different subject. They like ideas and issues to be discussed in a logical order. They like to refer to past experience and conversations to see how these might inform their current situations. They can be strongly opinionated and will speak out for and act on their own rights and the 
rights of others. Purposeful communicators may benefit from giving others time to express themselves, improving their group discussion skills and being able to discuss abstract ideas (Ferguson 2006, Hasson 2015). By getting to know one's communication style, person can learn how to develop more effective interpersonal relations with others and achieve greater psychological wellbeing. Accurate self-knowledge is truly the starting point for effectiveness at work. It is also essential for managing the three key relationships: relationships with self, with another person, and with members of a group. Patient satisfaction increases when patients feel that their nurses understand their needs and take these into consideration. Although previous studies have explored different aspects of nursing students' mental and psychological health in various countries (Mahrous\& Shehata 2015, Ratanasiripong \&Wang 2011, Yang and Zhou, 2008), little attention has been paid to investigate the psychological wellbeing in relation to communication styles of nursing students. Hence, the present study aimed to investigate the relationship between psychological wellbeing and communication styles among medical surgical nursing students.

\section{Aim of the study is:}

To assess the relationship between psychological wellbeing and communication styles among Medical-Surgical nursing students.

Research question: What is the relationship between psychological wellbeing and communication styles among Medical-Surgical nursing students?

\section{Materials and Method}

\section{Materials}

Design:

A descriptive correlational research design was utilized in this study.

Setting:

The study was conducted at Medical- Surgical Nursing Department, Faculty of Nursing, Alexandria University. Subjects:

The subjects of this study comprise all nursing students (174students) who were enrolled in Medical- Surgical Nursing III course and were available at the time of data collection in their clinical settings (Neuro-surgery, Urology, and Orthopedic).

Tools:

Tool I : Biosocio-demographic characteristics structured questionnaire sheet: It was developed by the researchers .It entailed information related to biosocio-demographic data of the students such as name, age, sex, residence, and their Grade Point Average (GPA).

Tool II: Ryff'sPsychologicalWellbeing (RPWB) scale : It was developed by Ryff in 1989. It assesses the students' psychological wellbeing and comprises of 42 items with 21 reversed items, each item consists of a series of statements reflecting the six areas of psychological wellbeing: autonomy, environmental mastery, personal growth, positive relations with others, purpose in life, and self-acceptance. Respondents rate statements on a scale of 1 to 6 , with 1 indicating strong disagreement and 6 indicating strong agreement.Autonomy : "I tend to be influenced by people with strong opinions", Environmental Mastery : "I am quite good at managing the many responsibilities of my daily life", Personal Growth: "I think it is important to have new experiences that challenge how you think about yourself and the world", Positive relations with others: "People would describe me as a giving person, willing to share my time with others", Purpose in Life: "Some people wander aimlessly through life, but I am not one of them", and Self-Acceptance: "In many ways I feel disappointed about my achievements in life" (reverse scored). Responses are totaled for each of the six categories. For each category, a high score indicates that the respondent has a mastery of that area in his or her life. Conversely, a low score shows that the respondent struggles to feel comfortable with that particular concept. Scale scores were computed as the sum of relevant items, reversing items where appropriate. These measures have adequate reliability (Alpha $=0.70-0.84$ ). (Ryff et al., 2006)

\section{Tool III: Communication style questionnaire:}

It was developed by Hasson (2012); it comprises 37self-reported statements for assessing students 'communication styles. It is composed of four communication styles namely: Active communicator style: consists of 10 statements, Connector style: includes 9 statements, Theorist style: consists of 9 statements, and Purposeful communicator style contains 9 statements. The respondents were ticked the statements that suit him/her on yes or no scale where; yes scored (1), while no scored (zero). The total score for each style was calculated, the greatest score for each style was considered the dominant style for each participant. If one had similar scores on two or more communications styles, this was considered a combiner style. The scale has adequate reliability (Alpha $=0.72)$. 


\section{Method}

- Official permission to conduct the study was obtained from the head of Medical- Surgical Nursing Department after explanation the purpose of the study- Tools II\& III were translated into Arabic and tested for the content validity by 5 experts in the fields Psychiatric and Medical- Surgical nursing and necessary modifications were done.-The reliability of Ryff"s psychological wellbeing scale and communication styles questionnaire with the test - retest were tested on 20Medical-Surgical nursing students. It produced an alpha coefficient of 0.74 , and 0.96 for both psychological wellbeing and communication styles questionnaires.-A pilot study was carried out on 20 students who were excluded from the study to test the feasibility and clarity of the tools. Accordingly, the necessary modifications were done. The questionnaire was administered individually to every student in one only of his/her specialty settings from each clinical rotation (Neurosurgical unit, Urology unit in the Main Alexandria University Hospital, and Orthopedic unit in Elhadara Hospital). Each rotation was 3 weeks. Every student was given the questionnaire at the second week from the rotation. It took about 30 minutes to complete it. The data were collected during the second term from the beginning of March 2016 till the end of April 2016.

\section{Ethical Considerations:}

- Informed written consent was obtained from the studied students after explaining the aim of the study.

- Data confidentiality was assured and maintained.

Students' privacy and anonymity were considered and respected .They were informed of their rights to decline participation or to participate voluntarily.

\section{Statistical Analysis}

Data were fed to the computer and analyzed using IBM SPSS software package version 20.0. Qualitative data were described using number and percent. Quantitative data were described using mean, standard deviation. Significance of the obtained results was judged at the 5\% level. Chi-square test was used for categorical variables, to compare between different groups, Monte Carlo correction ; correction for chi-square when more than $20 \%$ of the cells have expected count less than 5 .For normally quantitative variables, Student ttest was used to compare between two studied groups. In addition, F-test (ANOVA) was used to compare between more than two groups and Pearson coefficient were calculated to evaluate the relationship between variables. $\mathrm{P}$ value of $\leq 0.05$ used to assess the significance of the results.

\section{Results}

Table (1): Shows the distribution of the studied students according to their biosocio- demographic data, the results denoted that $58 \%$ of the students were 20 years old with mean age of $20.21 \pm 0.74$, more than two thirds (73\%) were female. $78 \%$ of them have been from urban, and $53.5 \%$ had GPA score with B grade.

Table (2): Illustrates the distribution of the studied students according to their psychological wellbeing (PWB) dimensions. The table revealed that personal growth dimension of psychological wellbeing has the highest percent score among the studied students followed by purpose in life $(68.6 \pm 16.18,61.43 \pm 15.01$ respectively). On the other hand, autonomy dimension documented the least percent score among the studied students $(52.7 \pm$ 13.61).Table (3): Reveals the distribution of the studied students according to their communication styles. The results revealed that more than half of the studied students (55.7\%) reported having connector communication style, while $22.4 \%$ reported having combiner style, $12.1 \%$ have theoretical style and 2.9 have purposeful style.

Table (4): Presents the relation between the studied students Psychological wellbeing (PWB) dimensions and Communication styles. A positive significant relationship was only found between positive relation dimension of psychological wellbeing and combiner communication style $(\mathrm{F}=2.931, \mathrm{p}=0.022)$, otherwise, no statistical significant difference was found between total psychological wellbeing and communication styles. ( $\mathrm{F}=0.940, \mathrm{P}=$ $0.442)$.

Table (5): Clarifies the relation between the studied students Psychological wellbeing (PWB) dimensions and Communication styles. A positive significant relationship existed between students PWB (positive relation) and combiner communication style $(\mathrm{t}=2.129$, and $\mathrm{p}=0.035)$. It was observed that the studied students with combiner style of communication received higher mean scores in positive relation dimension than those with only one style (62.64 \pm 14.65 and $57.12 \pm 14.13$ respectively). Table (6): Portrays the interrelations between the dimensions of psychological wellbeing among the studied nursing students, it was noticed that total psychological wellbeing has the strongest significant positive correlations with environmental mastery, personal growth and selfacceptance $(r=0.782,0.737 \& 0.773$ respectively), followed by purpose of life and positive relation $(r=$ $0.641 \& 0.621$ respectively). Environmental mastery has greater significant positive correlation with selfacceptance $(r=0.583)$ followed by personal growth and positive relation $(r=0.492 \& 0.429$ respectively). In addition, autonomy was correlated significantly positively total psychological wellbeing $(r=0.564)$. 
Table (7): Represents the relation between gender and communication styles among the studied students. It can be observed that more than half of male and female students reported having connector communication style (55.3 and 55.9 respectively), whereas, active style of communication was slightly increased among female students $(8.7 \%)$ than males $(2.1 \%)$ and theoretical communication style was slightly increased among male students $(14.9 \%)$ than females $(11.0 \%)$. Furthermore, male students reported having combiner style than female students $(25.5 \%, 21.3 \%$ consecutively), with no statistical significant difference was found between both groups.

Table (8): Shows comparison between male and female students in relation to their psychological wellbeing (PWB). It was observed that the mean scores of the total psychological wellbeing and its dimensions were higher in male students than females. Personal growth had higher mean score in male students $(72.28 \pm 16.1)$ than females $(67.24 \pm 16.06)$. In addition, total mean score was higher in male students $(62.0 \pm 10.44)$ than females $(59.3 \pm 10.7)$, with no significant difference was found between them.

Table (9): Illustrates the relation between the studied students GPA and communication styles. It was noticed that the majority of the studied students with GBA (A, B, C, and D\&F) reported having connector style of communication $(100 \%, 51.6 \%, 56.7 \%$, and 72.7 respectively), with no significant difference was found.

Table (10): Denotes the relation between Psychological wellbeing (PWB) dimensions and GPA among the studied students. The results denoted that there is no significant difference between students GBA and their PWB; the mean scores of six dimensions of PWB were nearly similar to each other in all students that had GBA score (A, B, C, and D\&F).

Table (1): Distribution of the studied students according to their biosocio-demographic data $(\mathrm{n}=174)$

\begin{tabular}{|c|c|c|}
\hline Biosocio-demographic data & No. & $\%$ \\
\hline $\begin{array}{l}\text { Age (years) } \\
19 \\
20 \\
21 \\
22\end{array}$ & $\begin{array}{c}23 \\
101 \\
40 \\
10\end{array}$ & $\begin{array}{c}13.2 \\
58.0 \\
23.0 \\
5.7\end{array}$ \\
\hline $\begin{array}{l}\text { Min. - Max. } \\
\text { Mean } \pm \text { SD. }\end{array}$ & \multicolumn{2}{|c|}{$\begin{array}{c}0.19-22.0 \\
20.21 \pm 0.74\end{array}$} \\
\hline $\begin{array}{l}\text { Gender } \\
\text { Male } \\
\text { Female }\end{array}$ & $\begin{array}{c}47 \\
127\end{array}$ & $\begin{array}{l}27.0 \\
73.0\end{array}$ \\
\hline $\begin{array}{l}\text { Residence } \\
\text { Urban } \\
\text { Rural }\end{array}$ & $\begin{array}{c}137 \\
37\end{array}$ & $\begin{array}{l}78.7 \\
21.3\end{array}$ \\
\hline $\begin{array}{l}\text { GPA } \\
\text { A } \\
\text { B } \\
\text { C } \\
\text { D+F }\end{array}$ & $\begin{array}{c}3 \\
93 \\
67 \\
11\end{array}$ & $\begin{array}{c}1.7 \\
53.5 \\
38.5 \\
66.3\end{array}$ \\
\hline
\end{tabular}

Table (2): Means of total percent score of psychological well-being dimensions among the studied students $(n=174)$

\begin{tabular}{|l|c|c|}
\hline $\begin{array}{l}\text { Psychological wellbeing } \\
\text { (PWB)dimensions }\end{array}$ & Total mean score & \% mean score \\
\hline Autonomy & $21.81 \pm 4.08$ & $52.7 \pm 13.61$ \\
\hline Environment Mastery & $27.12 \pm 5.47$ & $57.49 \pm 15.62$ \\
\hline Personal Growth & $31.01 \pm 5.66$ & $68.6 \pm 16.18$ \\
\hline Positive Relation with others & $27.43 \pm 5.04$ & $58.36 \pm 14.39$ \\
\hline Purpose in Life & $28.5 \pm 5.25$ & $61.43 \pm 15.01$ \\
\hline Self - Acceptance & $27.48 \pm 6.23$ & $58.52 \pm 17.79$ \\
\hline Total PWB & $168.05 \pm 22.40$ & $60.02 \pm 10.66$ \\
\hline
\end{tabular}


Table (3): Distribution of the studied students according to their communication styles $(\mathrm{n}=174)$

\begin{tabular}{|l|c|c||}
\hline \multicolumn{1}{|c|}{ Communication styles } & No. & \% \\
\hline Active communicator & 12 & 6.9 \\
Connector communicator & 97 & 55.7 \\
Purposeful communicator & 5 & 2.9 \\
Theoretical communicator & 21 & 12.1 \\
Combiner (More than one style) & 39 & 22.4 \\
\hline
\end{tabular}

Table (4): Relation between psychological wellbeing (PWB) and communication styles $(\mathrm{n}=174)$

\begin{tabular}{||l|c|c|c|c|c|c|c||}
\hline $\begin{array}{c}\text { Communication } \\
\text { styles }\end{array}$ & $\begin{array}{c}\text { Autonomy } \\
\text { Items }\end{array}$ & $\begin{array}{c}\text { Environment } \\
\text { Mastery }\end{array}$ & $\begin{array}{c}\text { Personal } \\
\text { Growth }\end{array}$ & $\begin{array}{c}\text { Positive } \\
\text { Relation }\end{array}$ & $\begin{array}{c}\text { Purpose in } \\
\text { Life }\end{array}$ & $\begin{array}{c}\text { Self - } \\
\text { Acceptance }\end{array}$ & Total PWB \\
\hline Active & $53.89 \pm 8.51$ & $51.19 \pm 12.39$ & $67.38 \pm 11.59$ & $57.38 \pm 12.21$ & $57.86 \pm 12.49$ & $60.0 \pm 12.36$ & $58.45 \pm 8.77$ \\
\hline Connector & $53.16 \pm 13.78$ & $59.09 \pm 15.62$ & $69.19 \pm 16.58$ & $58.59 \pm 14.34$ & $61.91 \pm 15.15$ & $58.85 \pm 18.68$ & $60.66 \pm 10.94$ \\
\hline Purposeful & $66.0 \pm 19.64$ & $61.71 \pm 10.99$ & $65.71 \pm 12.94$ & $59.43 \pm 10.58$ & $72.0 \pm 14.20$ & $67.43 \pm 24.88$ & $65.33 \pm 9.45$ \\
\hline Theoretical & $51.75 \pm 15.41$ & $51.43 \pm 15.57$ & $68.03 \pm 18.06$ & $49.66 \pm 13.29$ & $61.77 \pm 16.45$ & $54.83 \pm 17.46$ & $56.80 \pm 11.33$ \\
\hline Combiner & $50.0 \pm 12.04$ & $58.17 \pm 16.37$ & $68.21 \pm 16.31$ & $62.64 \pm 14.65$ & $59.78 \pm 14.65$ & $58.10 \pm 16.43$ & $59.98 \pm 10.24$ \\
\hline F(p) & $1.680(0.157)$ & $1.667(0.160)$ & $0.099(0.983)$ & $\begin{array}{c}2.931^{*} \\
\left(0.022^{*}\right)\end{array}$ & $0.934(0.445)$ & $0.568(0.686)$ & $0.940(0.442)$ \\
\hline
\end{tabular}

F: F value for ANOVA test

*: Statistically significant at $\mathrm{p} \leq 0.05$

Table (5): The relationship between psychological wellbeing (PWP) dimensions and Communication styles among the studied students $(\mathrm{n}=174)$.

\begin{tabular}{|c|c|c|c|c|}
\hline \multirow[b]{2}{*}{$\begin{array}{l}\text { Psychological wellbeing } \\
\text { (PWB)dimensions }\end{array}$} & \multicolumn{4}{|c|}{ Communication style } \\
\hline & $\begin{array}{l}\text { One style } \\
(n=135)\end{array}$ & $\begin{array}{l}\text { Combiner style } \\
\qquad(\mathbf{n}=38)\end{array}$ & $\mathbf{t}$ & $\mathbf{P}$ \\
\hline Autonomy & $53.48 \pm 13.98$ & $50.0 \pm 12.04$ & 1.411 & 0.160 \\
\hline Environment Mastery & $57.29 \pm 15.46$ & $58.17 \pm 16.37$ & 0.308 & 0.758 \\
\hline Personal Growth & $68.72 \pm 16.20$ & $68.21 \pm 16.31$ & 0.174 & 0.862 \\
\hline Positive Relation & $57.12 \pm 14.13$ & $62.64 \pm 14.65$ & $2.129^{*}$ & $0.035^{*}$ \\
\hline Purpose in Life & $61.90 \pm 15.13$ & $59.78 \pm 14.65$ & 0.778 & 0.438 \\
\hline Self - Acceptance & $58.65 \pm 18.22$ & $58.10 \pm 16.43$ & 0.170 & 0.865 \\
\hline Total PWB & $60.04 \pm 10.82$ & $59.98 \pm 10.24$ & 0.033 & 0.874 \\
\hline
\end{tabular}

Table (6): Inter-correlation between psychological wellbeingdimensionsamong the studied students

\begin{tabular}{|c|c|c|c|c|c|c|c|c|}
\hline $\begin{array}{c}\text { Psychological } \\
\text { wellbeing } \\
\text { dimensions }\end{array}$ & & $\begin{array}{c}\text { Autonomy } \\
\text { Items }\end{array}$ & $\begin{array}{c}\text { Environment } \\
\text { Mastery }\end{array}$ & $\begin{array}{c}\text { Personal } \\
\text { Growth }\end{array}$ & $\begin{array}{l}\text { Positive } \\
\text { Relation }\end{array}$ & $\begin{array}{c}\text { Purpose in } \\
\text { Life }\end{array}$ & $\begin{array}{c}\text { Self - } \\
\text { Acceptance }\end{array}$ & Overall \\
\hline \multirow{2}{*}{$\begin{array}{c}\text { Autonomy } \\
\text { Items }\end{array}$} & $\mathbf{R}$ & 1.000 & $0.368^{\text {***; }}$ & $0.253^{\text {***;* }}$ & $0.171^{3 * \pi}$ & $0.263^{\text {***;* }}$ & $0.405^{\text {**** }}$ & $0.564^{\text {**** }}$ \\
\hline & $\mathbf{P}$ & & $<0.001$ & 0.001 & 0.024 & $<0.001$ & $<0.001$ & $<0.001$ \\
\hline \multirow{2}{*}{$\begin{array}{c}\text { Environment } \\
\text { Mastery }\end{array}$} & $\mathbf{R}$ & & 1.000 & $0.492^{* * *}$ & $0.429^{* * * *}$ & $0.333^{* * *}$ & $0.583^{* * *}$ & $0.782^{* * * *}$ \\
\hline & $\mathbf{P}$ & & & $<0.001$ & $<0.001$ & $<0.001$ & $<0.001$ & $<0.001$ \\
\hline \multirow{2}{*}{$\begin{array}{l}\text { Personal } \\
\text { Growth }\end{array}$} & $\mathbf{R}$ & & & 1.000 & $0.384^{* * * *}$ & $0.474^{* * * *}$ & $0.390^{* * *}$ & $0.737^{* * * *}$ \\
\hline & $\mathbf{P}$ & & & & $<0.001$ & $<0.001$ & $<0.001$ & $<0.001$ \\
\hline \multirow{2}{*}{$\begin{array}{l}\text { Positive } \\
\text { Relation }\end{array}$} & $\mathbf{R}$ & & & & 1.000 & $0.234^{* * * *}$ & $0.374^{* * * *}$ & $0.621^{* * * *}$ \\
\hline & $\mathbf{P}$ & & & & & 0.002 & $<0.001$ & $<0.001$ \\
\hline Purpose in Life & $\mathbf{R}$ & & & & & 1.000 & $0.382^{* * * *}$ & $0.641^{* * * *}$ \\
\hline
\end{tabular}




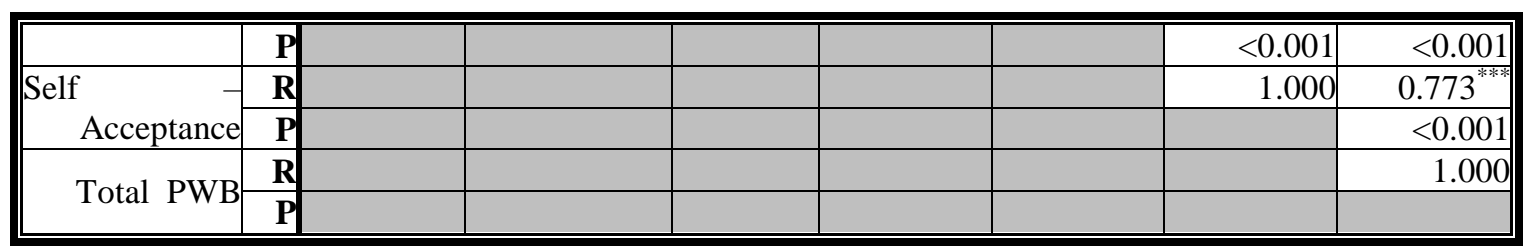

r: Pearson coefficient

*: Weak statistically significant $\leq 0.05-0.04$

$* *$ : Moderate statistically significant $0.039-0.011$

$* * *$ : Highly statistically significant $\leq \mathbf{0 . 0 1 0}$

Table (7): The relation between Gender and Communication styles among the studied students $(\mathrm{n}=174)$

\begin{tabular}{||l|c|c|c|c|c|c||}
\hline \multirow{2}{*}{ Communication styles } & \multicolumn{2}{|c|}{$\begin{array}{c}\text { Male } \\
(\mathbf{n = 4 7})\end{array}$} & \multicolumn{2}{c|}{$\begin{array}{c}\text { Female } \\
(\mathbf{n = 1 2 7})\end{array}$} & \multirow{2}{*}{$\chi^{\mathbf{2}}$} & \multirow{2}{*}{ P } \\
\cline { 2 - 7 } & No. & $\%$ & No. & $\%$ & & \\
\hline Active & 1 & 2.1 & 11 & 8.7 & 2.281 & 0.185 \\
\hline Connector & 26 & 55.3 & 71 & 55.9 & 0.005 & 0.945 \\
\hline Purposeful & 1 & 2.1 & 4 & 3.1 & 0.128 & 1.000 \\
\hline Theoretical & 7 & 14.9 & 14 & 11.0 & 0.484 & 0.487 \\
\hline Combiner & 12 & 25.5 & 27 & 21.3 & 0.360 & 0.548 \\
\hline
\end{tabular}

\section{$\chi^{2}$ : Chi square test}

Table (8): Comparison between male and females in relation to their psychological well-being (PWB) dimensions $(\mathrm{n}=174)$

\begin{tabular}{|l|c|c|c|c|}
\hline $\begin{array}{l}\text { Psychological well-being } \\
\text { PWB)dimensions. }\end{array}$ & $\begin{array}{c}\text { Male } \\
(\mathbf{n = 4 7 )}\end{array}$ & $\begin{array}{c}\text { Female } \\
(\mathbf{n = 1 2 7})\end{array}$ & T & P \\
\hline Autonomy Items & $53.83 \pm 14.6$ & $52.28 \pm 13.27$ & 0.664 & 0.507 \\
\hline Environment Mastery & $59.51 \pm 17.63$ & $56.74 \pm 14.82$ & 1.041 & 0.299 \\
\hline Personal Growth & $72.28 \pm 16.1$ & $67.24 \pm 16.06$ & 1.836 & 0.068 \\
\hline Positive Relation & $58.78 \pm 14.04$ & $58.2 \pm 14.57$ & 0.237 & 0.813 \\
\hline Purpose in Life & $63.47 \pm 13.41$ & $60.67 \pm 15.54$ & 1.089 & 0.277 \\
\hline Self-Acceptance & $61.82 \pm 17.73$ & $57.3 \pm 17.73$ & 1.494 & 0.137 \\
\hline Total PWB & $62.0 \pm 10.44$ & $59.3 \pm 10.7$ & 1.489 & 0.138 \\
\hline
\end{tabular}

\section{t: Student t-test}

Table (9):Relation between the studied students PA and Communication styles ( $\mathrm{n}=174)$

\begin{tabular}{|c|c|c|c|c|c|c|c|c|c|c|}
\hline \multirow[t]{2}{*}{$\begin{array}{l}\text { Communication } \\
\text { Styles }\end{array}$} & \multicolumn{2}{|c|}{$\begin{array}{c}A \\
(n=3)\end{array}$} & \multicolumn{2}{|c|}{$\begin{array}{c}\text { B } \\
(n=93)\end{array}$} & \multicolumn{2}{|c|}{$\begin{array}{c}C \\
(n=67)\end{array}$} & \multicolumn{2}{|c|}{$\begin{array}{c}D+F \\
(n=11)\end{array}$} & \multirow[t]{2}{*}{$\square^{2}$} & \multirow[t]{2}{*}{${ }^{\mathrm{MC}} \mathbf{p}$} \\
\hline & No. & $\%$ & No. & $\%$ & No. & $\%$ & No. & $\%$ & & \\
\hline Active & 0 & 0.0 & 7 & 7.5 & 5 & 7.5 & 0 & 0.0 & 0.602 & 1.000 \\
\hline Connector & 3 & 100.0 & 48 & 51.6 & 38 & 56.7 & 8 & 72.7 & 3.846 & 0.269 \\
\hline Purposeful & 0 & 0.0 & 2 & 2.2 & 2 & 3.0 & 1 & 9.1 & 3.127 & 0.453 \\
\hline Theoretical & 0 & 0.0 & 11 & 11.8 & 9 & 13.4 & 1 & 9.1 & 0.311 & 0.952 \\
\hline Combiner & 0 & 0.0 & 25 & 26.9 & 13 & 19.4 & 1 & 9.1 & 2.536 & 0.433 \\
\hline
\end{tabular}

$$
\chi 2 \text { : Chi square test }
$$

MC: Monte Carlo for Chi square test

Table (10): Relation between the studied students GPA and Psychological wellbeing (PWB) dimensions $(n=174)$.

\begin{tabular}{|c|c|c|c|c|c|c|c||}
\hline \multirow{2}{*}{$\begin{array}{c}\text { GPA } \\
\text { Score }\end{array}$} & \multicolumn{6}{|c|}{ Psychological wellbeing (PWB)dimensions } \\
& Autonomy & $\begin{array}{c}\text { Environment } \\
\text { Mastery }\end{array}$ & $\begin{array}{c}\text { Personal } \\
\text { Growth }\end{array}$ & $\begin{array}{c}\text { Positive } \\
\text { Relation }\end{array}$ & $\begin{array}{c}\text { Purpose } \\
\text { in Life }\end{array}$ & $\begin{array}{c}\text { Self }- \\
\text { Acceptance }\end{array}$ & Total PWB \\
\hline A & $54.44 \pm 16.44$ & $60.00 \pm 5.71$ & $65.71 \pm 11.43$ & $62.86 \pm 4.95$ & $64.76 \pm 7.19$ & $63.81 \pm 5.95$ & $62.54 \pm 6.05$ \\
\hline B & $54.12 \pm 13.45$ & $59.51 \pm 16.41$ & $70.69 \pm 15.21$ & $59.23 \pm 14.36$ & $62.92 \pm 15.17$ & $59.97 \pm 18.43$ & $61.61 \pm 10.84$ \\
\hline
\end{tabular}




\begin{tabular}{||c|c|c|c|c|c|c|c||}
\hline $\mathrm{C}$ & $51.09 \pm 13.63$ & $54.50 \pm 14.60$ & $65.84 \pm 17.23$ & $56.12 \pm 14.71$ & $59.36 \pm 14.38$ & $56.72 \pm 16.85$ & $57.80 \pm 9.97$ \\
\hline $\mathrm{D}+\mathrm{F}$ & $50.00 \pm 14.76$ & $57.92 \pm 15.23$ & $68.57 \pm 17.93$ & $63.38 \pm 13.39$ & $60.52 \pm 18.73$ & $55.84 \pm 20.30$ & $59.44 \pm 12.83$ \\
\hline $\mathrm{F}(\mathrm{p})$ & $0.807(0.492)$ & $1.374(0.253)$ & $1.203(0.310)$ & $1.202(0.311)$ & $0.790(0.501)$ & $0.602(0.614)$ & $1.745(0.160)$ \\
\hline
\end{tabular}

\section{F: F value for ANOVA test}

\section{Discussion}

Psychological wellbeing of nursing students has become crucial because of the multidimensional challenges that they have to deal with. It combined with feeling good and functioning efficiently to cope with any negative life experiences (Huppert 2009). Nursing students reported high levels of stress and anxiety during their training and described feelings of pressure because of the long hours and heavy workloads (Watkins et al. 2011). The cumulative effect of these new experiences and the students' way of communication in such experiences might have affected students' psychological wellbeing and left students overwhelmed and disempowered. The loss of control and the pressure the nursing students experienced might have impacted on their self-efficacy and made them particularly vulnerable to stressor events (Qiao, et al 2011). So the present study was conducted to assess the relationship between psychological wellbeing and communication styles among Medical -Surgical nursing students. The results of the present study revealed that the psychological wellbeing mean scores were relatively high among the studied students; personal growth has the highest mean score followed by purpose in life dimension. This may be related to the fact that occupations which focus on helping other people enable workers to fulfill their basic psychological need for relatedness (Spilt, et al 2011).This finding is supported by a study done by Ratanasiripong and Wang (2011); who found that nursing students have greater psychological wellbeing than non - nursing students. Regarding personal growth dimension, the reason for the highest mean score among the studied students in the present study may be justified by the fact that one has grown personally from experiencing frequent stressful events. Pals (2006) indicated that individuals often report a sense of having grown from the experience when they faced with a traumatic or stressful experience. In some way or another, these experiences are interpreted as having taught them something about themselves and about the world. They also found that reports of stress-related growth are in turn related to heightened wellbeing. IN this line, Ayub (2012) found that personal growth initiative is positively associated with psychological wellbeing and negatively associated with psychological distress among adolescences. Also, he found that those who are high in personal growth initiative and psychological wellbeing experience less mental health issues. According to the present findings, total psychological wellbeing was significantly and positively correlated with purpose of life and positive relation with others among the studied nursing students. This result can be attributed to the other present finding which revealed that more than half of the studied students reported having connector style of communication. Those who have connector style of communication tend to use tact and diplomacy skills which centered on an understanding of other people and being sensitive to their opinions, beliefs, ideas and feelings. They gather perspectives from multiple people and allow new people to join their established groups. They are flexible and adaptable if they understand why the changes are being made and how they will benefit themselves and others. They seek to reduce stress and promote harmony, handle conflict and disagreement diplomatically and are being supportive. Similarly, Mascaro, et al. (2004) found that the majority of nursing students experienced sense of purpose and deep meaning; participants conveyed the realization that they had a specific role to fulfill regardless of their own personal challenges. They claimed that nursing is not just a job; it's a love for the work, the people and to help people. A study conducted by Cenkseven (2004) who examined the predictors of subjective and psychological wellbeing of university students reported that there is negative correlation between purposes in life, depression, and positive correlation with self-esteem. Moreover, the individuals who have high loneliness levels are not satisfy with her/him life, because of having lots of psychological problems as; anxiety, depression, and low self-esteem. Personal wellbeing means that individuals have the autonomy to make decisions in their lives, feel a sense of control over the pressures and experience optimism and meaning in their lives. Autonomy dimension in the present study was the least mean percent score among the studied students. Consistent with this finding; Watkins et al (2011) study aimed to explore the different dimensions of wellbeing as described by nursing students, they found that participants had no autonomy over their practical-training hours. Moreover, they believed that they should have been given the freedom to allocate their own training times so that they could decide when they could go home on weekends and when they could not. They also believed that they were not allowed to use their own initiative when faced with difficult situations in their practical training. They felt as though all they were allowed to do was to stand back, to observe and to let things happen to them and around them. Third-year participants confirmed the lack of autonomy they had expressed during their first year although it appears that they were granted more autonomy in their third year. The participants still experienced a lack of autonomy in government hospitals but reported that they had more responsibility in private hospitals, which made them feel more empowered. A study done by Ponto M. (2011) aimed to explore nursing students'

\begin{tabular}{llr|l}
\hline DOI: $10.9790 / 1959-0601047585$ & www.iosrjournals.org & $82 \mid$ Page
\end{tabular}


perceptions of autonomy; Interpretative Phenomenological Analysis was used for data collection and analysis. He concluded that nursing educators did not promote autonomous functioning and personal development for nursing students.

In the present study, a positive and significant correlation between students PWB (positive relation) and combiner communication style was found. Those who use combiner communication style documented higher percent score in positive relation dimension of psychological well-being than those with one communication style. A' combiner ' communicators can mix and match all four communication styles to adapt themselves to suit their audience. (Dorgham\&Al.Mahmoud2013). A similar study conducted by Maria (2010) to investigate the association between assertiveness and psychological wellbeing among adult students. $\mathrm{He}$ found a significant positive relationship between assertive behavior of students and their psychological wellbeing. Another study by Sarkova et al, (2010) was conducted to explore the association between assertive behavior of adolescents, psychological well-being and self-esteem; they indicated that assertiveness was confidently associated with psychological well-being and self-esteem. According to the present finding, connector style of communication was nearly distributed equally among male and female students, this may be attributed to the fact that nursing as a profession needs masculinity and femininity attributes to meet the job demands. Feminine attributes such as being caring and empathetic are the core elements of patient care. Therefore, nursing students in the faculty trained to incorporate these attributes through the course of communication skills and human relations in the second semester before enrolling in Medical -Surgical nursing course. The learning objectives of this course concerned with gender differences in communication aimed to identify the differences in the way men and women communicate, both verbally and non-verbally and demonstrate successful female - male communication. This result was in congruent with the study of Shafiq et al (2015) who found no significant statistical differences regarding communication styles and psychological wellbeing among university students. In contrast, Eskin (2003) indicated that there was gender difference in communicating thoughts and dealing with personal restrictions, where females were found to be more capable than males. However, the present study finding demonstrated gender differences in aspects of communication styles and psychological wellbeing among the studied students. Theoretical and combiner communication styles and psychological wellbeing were increased among male students than females. This may be as a result of basic biological differences and cultural behavioral expectations between males and females. According to the theory of gender-role socialization, males are oriented toward mastery and exploration of the world while females are oriented toward interpersonal relationships. Masculine attributes like power and strength are the basis for fruitful interdisciplinary cooperation and autonomy (Perez J 2012). This finding was supported by the significant relation between combiner style and psychological wellbeing in the present finding. In the same line,Akhter (2015) found that male and female students are differing significantly in psychological wellbeing. Inversely to the present finding, Rathi and Rastogi (2007) found no differences between males and females on psychological well-being subscales. Concerning to communication styles and psychological wellbeing in relation to students' academic achievement. Although many studies have found a relationship between academic achievement and both correlates, the present findings have found that academic achievement was not correlated with communication style and psychological wellbeing. These results may be attributed to the students' work, where psychological wellbeing and communication styles are largely influenced by other personal and professional factors instead of academic ones. Similarly, Clifton, and Henrique (2015) examined the relationship between Intelligence and psychological wellbeing in incoming college students, their study revealed that for the sample of young adults, more intelligent students reported having lower psychological wellbeing. On contrast to the present findings, Frymier and Houser (2000) noted that following variables having a relationship to learning and achievement: immediacy, effective communication, affinity-seeking, compliance gaining, humor, and caring.

\section{Conclusion}

The main results of the present study revealed that personal growth dimension of psychological wellbeing has the highest percent score among the studied students followed by purpose in life, whereas autonomy dimension documented the least percent score among the studied students. A positive significant relationship was found between positive relation dimension of psychological wellbeing and combiner communication style.

\section{Recommendations}

Based on the results of the present study, it was recommended that:

- Nursing curricula can capitalize on promoting students' psychological wellbeing through education, role modeling and effective communication.- Student nurses should be connected to an interactive web wellness portal with tools and resources for optimal psychological wellbeing based on specific risks and interests.

- Nursing educators should provide a safe learning environment which is satisfying, promotes autonomous functioning and encourages self-governance and personal growth for nursing students.-Implementing counseling services for nursing students is imperative to cope with academic, social and emotional 
stressors.-Teaching students stress management techniques as part of the course may help them to cope with the pressures and demands they are exposed to. -Weekly group sessions, where students can share experiences outside the classroom environment, may be beneficial to the students' psychological wellbeing.- Future research should investigate the relationships between psychological wellbeing, in light of coping with stressful situations, personal growth, autonomy and interpersonal relationship.- This study should be replicated with a larger population in different nursing specialties.

\section{References}

[1] Ayub N. The relationship between personal growth initiatives, psychological distress, and psychological well-being among adolescents.Journal of Teaching in Physical Education 2012; 1(6):

[2] Andrews D.R., Wan TT. The importance of mental health to the experience of job strain: an evidence-guided approach to improve retention. Journal of Nursing Management. 2009; 17:340-51.

[3] Akhter S. Psychological Well-Being in Student of Gender Difference .The International Journal of Indian Psychology 2015; 2, (4): ISSN 2348-5396 (e) ,ISSN: 2349-3429 (p) .

[4] Bernstein S. A Positive Outcome from 2016 http://www.dlapiperwin.com/export/sites/win/downloads/DLA-Piper-Positive-Outcomes-From-Difficult-Conversations.pdf

[5] Chant S, Jenkinson T, Randle J, Russell G. Communication skills: some problems in nursing education and practice. Journal of Clinical Nursing. 2002; 11(1):12-21.

[6] Cenkseven, F. Examining the predictors of subjective and psychological well-being of university students, Unpublished Phd. Thesis, 2004. Çukurova University, Adana.

[7] Clifton J., HenriquesR.The Relationship between Intelligence and Psychological Well-Being in Incoming College Students. Psychology of Well-Being Theory, Research and Practice .2015; 5:4.

[8] Deci E. L., \& Ryan, R. M.Facilitating optimal motivation and psychological well-being across life's domains.Canadian Psychology.2008; 49, $14-23$.

[9] DorghamShR, Al.Mahmoud SA. Leadership styles and clinical decision making autonomy among critical care nurses: a comparative study. IOSR J Nurs Health Sci 2013; 1(4):71-83.

[10] Eskin, M. Self-reported assertiveness in Swedish and Turkish adolescents: A cross-cultural comparison. Scandinavian Journal of Psychology.2003, 44: 7-12.

[11] Ferguson P. Styles of Communication. 2006. Available at: www.scu.edu.au/schools/gcm.

[12] Frymier A., \& Houser ML.The teacher-student relationship as an interpersonal relationship.Communication Education.2000; 49: 207-19.

[13] Gibbons, C. Stress, coping and burn-out in nursing students. International Journal of Nursing Studies 2010; 47, $1299-1309$.

[14] Galinha I, \&Pais-Ribeiro, J. Cognitive, affective and contextual predictors of subjective wellbeing. International Journal of Wellbeing. 2011; 2(1), 34-53.

[15] HassonG.Brilliant Communication Skills: What the Best Communicators Know, Do and Say.PublishedJanuary 27th 2012 by Pearson Education.

[16] [-Hishinuma, E, Chang, J., McArdle, J. \& Hamagami, F. Potential causal relationship between depressive symptoms and academic achievement in the Hawaiian high schools health survey using contemporary longitudinal latent variable change models.Developmental Psychology.2012; 48, 1327-42.

[17] Huppert, F. A. Psychological well-being: Evidence regarding its causes and consequences. Applied psychology: health and wellbeing. 2009; 1 (2): 137-64

[18] Jimenez C., Navia-Osorio, P., \& Diaz, C. Stress and health in novice and experienced nursing students. Journal of Advanced Nursing.2010; 66(2), 442-55.

[19] https://www.scribd.com/doc/122919563/Communication-Styles-Lesson -Jones G. Understanding Communication Styles 2015 . Available at

[20] https://www.scribd.com/doc/122919563/Communication-Styles-Lesson

[21] KourkoutaL, PapathanasiouI. Communication in Nursing Practice. Journal of the academy of medical sciences of Bosnia and Herzegovina. $2014 ; 26(1)$ : 65-7.

[22] [-Leonard M., Graham S., \&Bonacum, D. The human factor, the critical importance of effective teamwork and communication in providing safe care.Quality \& Safety in Health Care. 2005; 13, 85-90. Mahrous E, Shehata A. Perceived stress and coping strategies among nursing students at Ras Al khamaima Medical and Health Science University in the United Arab Emirates. Alexandria Scientific Nursing Journal 2015; 17 (2): 21-36.McCabe C. Nurse-patient communication: an exploration of patients' experiences. Journal of Clinical Nursing.2004; 13(1):41-9.

[23] Meyer G., \&Arnheim, L. The power of two improving patient safety through better physician-patient communication. Family Practice Management 2002; 9: 47-60.

[24] [-Mascaro N., Rosen, D.H. \& Morey, L.C., 'The development, construct validity, and clinical utility of the spiritual meaning scale', Personality and Individual Differences2004;37(4):845-60.

[25] Maria S. The associations between assertiveness and psychological wellbeing in Slovak adolescents.Journal of Social Applied Psychology 2010; 78, $478-98$.

[26] Nayeri ND., Negarandeh R., Vaismoradi M., Ahmadi, F., Faghihzadeh, S. Burnout and productivity among Iranian nurses. Nursing \& Health Sciences. 2009; 11:263-70.

[27] Pals JL. Narrative identity processing of difficult life experiences: Pathways of personality development and positive selftransformation in adulthood. Journal of Personality 2006; 74: 1079-1110.

[28] Ponto M. Nursing students' perceptions of autonomy: A qualitative study Prog Health Sci 2011; 1 (2): 1-7.

DOI: 10.9790/1959-0601047585 $\quad$ www.iosrjournals.org $84 \mid$ Page


[29] Perez J. Gender Difference in Psychological Well-being among Filipino College Student samples.International Journal of Humanities and Social Science 2012;2 (13): 1-10

[30] Qiao G., Li S. \& Hu J. Stress, coping and psychological well-being among new graduate nurses in China.Home Health Care Management and Practice 2011; 23 (6): 398-403.

[31] Ratanasiripong P., Wang CC. Psychological well-being of Thai nursing students.NurseEduc today. 2011; 31(4):412-6.

[32] Ryff, C. D., \& Singer, B. H. (2006). Best news yet on the six-factor model of well-being.SocialRyff, C. D., \& Singer, B. H. (2006).Best news yet on the six-factor model of well-being.Social Science

[33] [Research, 35, 1103-1119.

[34] Ryff, C. D., \& Singer, B. H. Best news yet on the six-factor model of well-being. Social Science Research $2006 ; 35$, $1103-1119$.

[35] Rella S., Winwood P.C., Lushington K. When does nursing burnout begin? An investigation of the fatigue experience of Australian nursing students. Journal of Nursing Management. 2009; 17:886-97.

[36] -Reader T., Flin, R., \&Cuthbertson, B. Communication skills and error in the intensive care unit. Current Opinion in Critical Care.2007; 13, 732-36.

[37] Rathi N, RastogiR.Meaning in Life and Psychological Well-Being in Pre-Adolescents and Adolescents Journal of the Indian Academy of Applied Psychology 2007; 33(1): 31-8.

[38] Sarvestani SR, Moattari M, Nikbakht N. A, Momennasab M, YektatalabS.h. Challenges of nursing handover: a qualitative study. Clinical Nursing Research. 2013; 10.1177/1054773813508134

[39] Shojaee M, French C. The Relationship between Mental Health Components and Locus of Control in Youth. Psychology 2014, 5, 966-978. Available at:

[40] http://www.scirp.org/journal/psych http://dx.doi.org/10.4236/psych.2014.58107

[41] Shultz M. Factors related to stress in nursing students 2011. Available at:-

[42] http://stars.library.ucf.edu/cgi/viewcontent.cgi?article=2182\&context=honorstheses1990-2015

[43] Spilt J, KoomenH,ThijsJ. Teacher Wellbeing: The Importance of Teacher-Student Relationships.Springer2011; 20 (1):ISSN 1040726X

[44] Sarkova M., et al .Associations between assertiveness, psychological well-being, and self-esteem in adolescents. Journal of Applied Social Psychology .2010; 43:147-54.

[45] ShafiqS, Naz R, Yousaf B. Gender Differences between Assertiveness and Psychological Wellbeing among University Students. Educational Research International. 2015 4(2): 2307-3721.

[46] Watkins K, Roos V, Walt E. An exploration of personal, relational and collective well-being in nursing students during their training at a tertiary education institution.Journal of Interdisciplinary Health Sciences. 2011; 16(1): 1-10.

[47] Xie J, Ding S, Wang C, Liu A. An evaluation of nursing students' communication ability during practical clinical training. Nurse Education Today. 2013; 33(8):823-27.

[48] -Yang, H., Zhou, S.,.Relationship among adult attachment, parenting styles and self-esteem of female nursing students. Chinese Journal of Clinical Psychology 2008; 16, 189-91.

[49] Zamani A, Shams B, Moazzam E. Communication skills training for physicians as a strategy for enhancing patients' satisfaction: a model for continuing education. Iranian Journal of Medical Education. 2004; 4(1):15-20.

[50] Global Journal of Health Science; Vol. 7, No. 4; 2015 